\title{
Is There a Need for New Surgical Procedures for Glaucoma? Yes!
}

\author{
George L. Spaeth, Victor Cvintal and Ana Figueiredo
}

Glaucoma Service, Wills Eye Institute, 840 Walnut St, Philadelphia, PA 19107, USA

\begin{abstract}
The only method to slow or stop progressive damage caused by glaucoma, the leading cause of irreversible blindness, definitively shown to be effective, is lowering intraocular pressure, though there is also evidence that stabilizing the pressure may be beneficial. Performing surgery on the eye has proven effective in some cases, using various techniques, though with variable frequencies of success (stabilization of the disease) and various frequencies and severities of complications. Surgery offers the great advantage of longer duration of action than medicinal treatments presently available, and, also, of lessening the need of the patient to be faithful using suggested medications. There is a need to develop surgical procedures which will be effective in 1) lowering or stabilizing intraocular pressure in a way most likely to prevent glaucomatous deterioration, 2) causing the fewest and least severe problems, and 3) being the most economical. Recent efforts in this regard are promising, but not yet proven superior to well-performed trabeculectomy, itself an evolving procedure.
\end{abstract}

Keywords: Complications, Cost/benefit ratio, cost effectiveness, effectiveness, glaucoma, guarded filtration procedure, minimally invasive glaucoma surgery, surgery, trabeculectomy.

\section{INTRODUCTION}

If there were a very safe, very effective surgery for glaucoma, glaucoma would no longer be the leading cause of irreversible blindness. To consider the future, it is often helpful to examine the present. There are three different ways to consider the fact that surgical treatment for glaucoma is in many ways quite similar to the surgery that was performed 50 or even 100 years ago. It could be a sign of lack of innovation or creativity, or, on the other hand, it could be an indication of the brilliance of the individuals who first developed surgery at the close of the $19^{\text {th }}$ Century. A third interpretation would be that advancing the art and science of glaucoma surgery is so extraordinarily difficult that there really have been almost no viable options other than those methodologies developed many years ago [1-6].

Because current glaucoma surgeries are difficult and often associated with complications, there is great interest in developing new surgical procedures. The impetus for this is driven by two different considerations: in the first place, the current standard, trabeculectomy, is a difficult operation, labor intensive, and, as often performed, accompanied by complications, both short term and long term. Some surgeons do not feel an urgency about developing new surgery because they are quite comfortable with the performance of trabeculectomy and, in their hands, the complication rate is remarkably low. The senior author of this paper, for example, is still enthusiastic about trabeculectomy as a fine operation. His papers appear to indicate that flat anterior chambers, excessively soft eyes, leaking filtration blebs, and ophthalmitis are uncommon

*Address correspondence to this author at the Glaucoma Service, Wills Eye Institute, 840 Walnut St, Philadelphia, PA 19107, USA;

Tel/Fax: 215-928-3123; E-mail: dmalony@willseye.org
[7-13]. Furthermore, reviews by Watson, Ridgway, and others suggest a long term success rate in the 80 percent range, the procedure lasting for the duration of the patient's life [14-17]. These results, however, are in contrast to many other studies from centers where surgeons are clearly highly competent and a great deal of surgery is performed [18-23]. A general consensus has developed that trabeculectomy tends to fail after about five years in around 50 percent of the cases [18-20, 22-25].

The second driving force fueling the interest in newer types of glaucoma surgery relates to a complication rate which accompanies the "usual" way in which trabeculectomy is performed, and which is disturbingly high. Underlying this difference in rate of complications of "trabeculectomy" is a remarkable lack of agreement as to how to perform the operation [26]. Indeed the very name, trabeculectomy, itself is confusing, because as currently performed, very few surgeons actually excise trabecular meshwork. The operation should more accurately be called a guarded keratosclerectomy, or, more simply, a guarded filtration procedure.

The search for an optimal way to lower intraocular pressure in patients with glaucoma is not new. Trabeculectomy itself was developed as a way to decrease the rate of complication from full thickness filtration procedures $[14,17,27-31]$. The concept of a "guarded filtration procedure" was advanced by Shaffer and others $[31,32]$.

An additional reason why there is an interest in developing filtering glaucoma surgery relates to the obvious problems that many patients do not take medications as suggested, many patients do not have access to medications and cannot keep the frequent office appointments that are required in order to be sure that the medications are working, 
and many patients cannot afford the costs of years of treatment with the medications. Were a very effective, very safe glaucoma procedure available, the likelihood is that it would be widely utilized and would result in a gratifying and substantial decrease in the now disturbingly large number of individuals who lose vision from glaucoma, which is the leading cause of irreversible blindness in every country in the world [33-35]. Furthermore, it is likely that this disturbing statistic will become even more disturbing because glaucoma is more frequent in the elderly and the world's population is aging markedly [36-38].

This brief review of the history of glaucoma surgery up to the present is necessary before speculating about what will happen in the future. Also necessary is an understanding of when surgery is necessary and what it aims to accomplish. In the simplest terms, were it possible to perform a surgical procedure that would be 100 percent successful in preventing the development of progressive optic nerve damage and do it without causing complications, it would be possible to eliminate many of the tests that are presently required to determine if a person really does have glaucoma and if he or she is getting worse, and at what rate. At the present, the only justification for any treatment of any kind, including surgery, is a relative certainty that without treatment the person will develop a decrease in quality of life and a disability. Every treatment that we have at present itself causes some type of decrease in quality of life, and that includes both medical and surgical treatments. From a theoretical point of view, then, a totally effective, totally safe treatment would be a complete game changer, because then it would be possible to operate on people in whom the future was uncertain, but in whom there was a reasonable likelihood that they might develop a decreased quality of life or disability related to glaucoma. Is such a goal possible to achieve? The answer is, "no," when one considers the current approaches to glaucoma surgery.

Glaucoma is a process in which tissues become damaged, most particularly the optic nerve. If vision is lost because the optic nerve becomes damaged, it is conceivable that it would be possible to strengthen the lamina cribrosa. This could be done by a nanotechnological method that might impregnate the lamina with cellular material and endogenous connective tissue, or even an exogenous plastic. Patients with ocular hypertension have an abnormally thick lamina cribrosa. While it is possible that the elevation of intraocular pressure stimulates the development of such a protective barrier, the more probable theory is that patients who (for whatever reason) have thicker lamina cribrosas are less likely to develop glaucomatous optic nerve damage because the thicker lamina protects the nerve fibers more carefully than the lamina that is thinner. What is conceivable is that providing support to the connective tissue surrounding the optic nerve would prevent the nerve from enlarging, and could perhaps prevent the enlarging nerve from damaging the neurons as they pass through the lamina.

Another approach would be to develop a micro tubular network that would lie on the surface of the globe, and would be connected to a stent in Schlemm's canal (an extension of the current stent technology). It might be possible to develop an artificial bleb connected to a sclerectomy opening from the anterior chamber, similar to the sclerectomies presently made during full thickness or guarded filtration procedures. This artificial bleb would have a programmable surface allowing more or less aqueous to filter through it underneath the conjunctiva.

Nano technology could possibly create a pressure sensitive trabecular meshwork. A different approach would be infiltrating the ciliary body secretory cells with tiny, programmable chemical structures that would suppress aqueous production.

Having proposed some truly novel approaches to the surgical treatment of glaucoma, we wish to return to what is more realistic, more immediate, and more likely to occur, specifically, continuing revision and modification of guarded filtration procedure. It is likely that continued experimentation will result in improvement, due to new agents that will modulate wound healing, continuing development of the use of releasable or modifiable sutures, ways to measure aqueous production inexpensively and reliably, and, importantly, better understanding of the genetic characteristics which predispose to certain types of outcomes.

While the existence of a filtering bleb is frequently looked on as a negative, the bleb may constitute a type of decompression chamber, which may explain the remarkable stability of intraocular pressure throughout the day and over the years that is associated with successful guarded filtration procedures. It is unlikely that surgeons will abandon a procedure which continues to be improved and continues to be effective in preventing visual loss in those with the single largest cause of irreversible blindness. Better ways of regulating intraocular pressure around the time of surgery will also be found with regards to tube shunt procedures, increasing their already great value.

In summary, it is likely that filtration procedures in various forms will continue to be the work horses of glaucoma surgery, with increasing ability to personalize the technique of surgery depending upon the particular needs of the individual patient, related to genotype, inflow, amount of optic disc damage, rapidity of deterioration, styles characteristics, and many other considerations.

\section{CONFLICT OF INTEREST}

The authors confirm that this article content has no conflict of interest.

\section{ACKNOWLEDGEMENTS}

Declared none.

\section{REFERENCES}

[1] Elliot R. A preliminary note on a new operative procedure for the establishment of a filtering cicatrix in the treatment of glaucoma. Ophthalmoscope 1909; 7: 804

[2] Herbert H. The Operative Treatment of Glaucoma. New York NY: William Wood 1923.

[3] Sugar H. The Glaucomas. 2ndī ed. New York, NY: Hoeber-Harber 1957.

[4] Heine L. Die Cyclodialyse, eine neue glaukomoperation. Dtsch Med Wochenschr 1905; 31(21): 824-6. 
[5] Graefe Av, Windsor T. Three memoirs on iridectomy in certain forms of iritis, choroiditis, and glaucoma. London: New Sydenham Society $1859 ; 1$ : pp. 240-380.

[6] Bowman W. Operations on The Eye. London: Longman, Brown, Green, and Longmans 1849; p.2.

[7] Araujo SV, Spaeth GL, Roth SM, Starita RJ. A ten-year follow-up on a prospective, randomized trial of postoperative corticosteroids after trabeculectomy. Ophthalmology 1995; 102(12): 1753-9.

[8] de Barros DS, Navarro JB, Mantravadi AV, et al. The early flat anterior chamber after trabeculectomy: a randomized, prospective study of 3 methods of management. J Glaucoma 2009; 18(1): 1320.

[9] Katz LJ, Cantor LB, Spaeth GL. Complications of surgery in glaucoma. Early and late bacterial endophthalmitis following glaucoma filtering surgery. Ophthalmology 1985; 92(7): 959-63.

[10] Razeghinejad MR, Fudemberg SJ, Spaeth GL. The changing conceptual basis of trabeculectomy: a review of past and current surgical techniques. Surv Ophthalmol 2012; 57(1): 1-25.

[11] de Barros DS, Da Silva RS, Siam GA, et al. Should an iridectomy be routinely performed as a part of trabeculectomy? Two surgeons' clinical experience. Eye (London, England) 2009; 23(2): 362-7.

[12] Spaeth GL, Joseph NH, Fernandes E. Trabeculectomy: a reevaluation after three years and a comparison with Scheie's procedure. Ophthal Surg 1975; 6(1): 27-38.

[13] Spaeth GL. "Guarded filtration procedure"--not "trabeculectomy". Ophthalmic Surg 1992; 23(9): 583.

[14] Landers J, Martin K, Sarkies N, Bourne R, Watson P. A twentyyear follow-up study of trabeculectomy: risk factors and outcomes. Ophthalmology 2012; 119(4): 694-702.

[15] Ridgway AE. Trabeculectomy. A follow-up study. $\mathrm{Br} \mathrm{J}$ Ophthalmol 1974; 58(7): 680-6.

[16] Ridgway AE, Rubinstein K, Smith VH. Trabeculectomy. A study of 86 cases. Br J Ophthalmol 1972; 56(7): 511-6.

[17] Watson PG, Barnett F. Effectiveness of trabeculectomy in glaucoma. Am J Ophthalmol 1975; 79(5): 831-45.

[18] Gedde SJ, Heuer DK, Parrish RK 2nd, Tube Versus Trabeculectomy Study G. Review of results from the tube versus trabeculectomy study. Curr Opin Ophthalmol 2010; 21(2): 123-8.

[19] Gedde SJ, Schiffman JC, Feuer WJ, et al. Three-year follow-up of the tube versus trabeculectomy study. Am J Ophthalmol 2009; 148(5): 670-84.

[20] Gedde SJ, Singh K, Schiffman JC, Feuer WJ. The Tube Versus Trabeculectomy Study: interpretation of results and application to clinical practice. Curr Opin Ophthalmol 2012; 23(2): 118-26.

[21] Aktas Z, Korkmaz S, Hasanreisoglu M, Onol M, Hasanreisoglu B. Trabeculectomy with large area mitomycin-C application as a firstline treatment in advanced glaucoma: retrospective review. Int $\mathrm{J}$ Ophthalmol 2014; 7(1): 104-9.
[22] Kirwan JF, Lockwood AJ, Shah P, et al. Trabeculectomy in the $21^{\text {st }}$ century: a multicenter analysis. Ophthalmology 2013; 120(12): 2532-9.

[23] Saheb H, Gedde SJ, Schiffman JC, Feuer WJ. Outcomes of glaucoma reoperations in the tube versus trabeculectomy (TVT) study. Am J Ophthalmol 2014; 157(6): 1179-89.e2.

[24] Chai C, Loon SC. Meta-analysis of viscocanalostomy versus trabeculectomy in uncontrolled glaucoma. J Glaucoma 2010; 19(8): 519-27.

[25] Jonescu-Cuypers C, Jacobi P, Konen W, Krieglstein G. Primary viscocanalostomy versus trabeculectomy in white patients with open-angle glaucoma: a randomized clinical trial. Ophthalmology 2001; 108(2): 254-8

[26] Almeida G, Zangalli C, Alencar L, Hatanaka M, Ferreira E, Spaeth G. Variability of trabeculectomy among glaucoma surgeons: a survey from different countries. Invest Ophthalmol Vis Sci 2013; 54: E-Abstract 3508.

[27] Cairns JE. Trabeculectomy. Preliminary report of a new method. Am J Ophthalmol 1968; 66(4): 673-9.

[28] Cairns JE. Symposium: microsurgery of the outflow channels. Trabeculectomy. Opthalmology 1972; 76(2): 384-8.

[29] Cairns JE. Surgical treatment of primary open-angle glaucoma. Trans Ophthalmol Soc UK 1972; 92: 745-56.

[30] Cairns JE. Clear-cornea trabeculectomy. Trans Ophthalmol Soc UK 1985; 104 (Pt 2): 142-5.

[31] Dellaporta A, Fahrenbruch RC. Trepano-trabeculectomy. Opthalmology 1971; 75(2): 283-95.

[32] Shaffer RN, Hetherington J, Jr., Hoskins HD, Jr. Guarded thermal sclerostomy. Am J Ophthalmol 1971; 72(4): 769-72.

[33] Foster PJ, Buhrmann R, Quigley HA, Johnson GJ. The definition and classification of glaucoma in prevalence surveys. Br J Ophthal 2002; 86(2): 238-42.

[34] Leske MC. Open-angle glaucoma -- an epidemiologic overview. Ophthal Epidemiol 2007; 14(4): 166-72.

[35] Quigley HA, Broman AT. The number of people with glaucoma worldwide in 2010 and 2020. Br J Ophthal 2006; 90(3): 262-7.

[36] Ageing and Life Course WHO. Care and independence in older age Geneva, Switzerland: WHO 2014 [cited 2014 6/6/2014]. Available from: http://www.who.int/ageing/en/

[37] Guedes G, Tsai JC, Loewen NA. Glaucoma and aging. Curr Aging Sci 2011; 4(2): 110-7.

[38] Haub C. World Population Aging: Clocks Illustrate Growth in Population Under Age 5 and Over Age 65 Washington, DC: Population Reference Bureau 2013 [cited 2014 6/6/2014]. Available from: http://www.prb.org/Publications/ Articles/2011/ agingpopulationclocks.aspx

Received: March 28, 2015

Revised: March 30, 2015

Accepted: March 30, 2015

\section{(C) Spaeth et al.; Licensee Bentham Open.}

This is an open access article licensed under the terms of the Creative Commons Attribution Non-Commercial License (http://creativecommons.org/licenses/by-nc/3.0/) which permits unrestricted, non-commercial use, distribution and reproduction in any medium, provided the work is properly cited. 